\title{
Phylogenetic analysis of spring viraemia of carp virus isolates from Austria indicates the existence of at least two subgroups within genogroup Id
}

\author{
A. Basic, O. Schachner, I. Bilic, M. Hess* \\ Clinic for Avian, Reptile and Fish Medicine, Department for Farm Animal and Veterinary Public Health, \\ University of Veterinary Medicine Vienna, Veterinärplatz 1, 1210 Vienna, Austria
}

\begin{abstract}
Genetic relationships between 22 spring viraemia of carp virus (SVCV) isolates from Austria collected between 1994 and 2007 were determined based on the partial nucleotide sequence of the glycoprotein gene (G gene). Phylogenetic analyses located all Austrian isolates except one in genogroup Id. One isolate collected in 2007 was placed within the SVCV Ia genogroup. More importantly, the study also revealed 3 distinct clusters within genogroup Id, designated Id1, Id2 and Id3. Existence of subgroups Id2 and Id3 within the genogroup Id was supported by high bootstrap values. The genetic clustering could neither be linked to host species nor to geographic localization of fish farms. Furthermore, no clear link could be established between the pathological lesions and phylogenetic relationship. However, time-dependent division of the isolates was observed. Viruses from the Id1 cluster were mainly sampled in Austria in the 1990s and up until 2003, whereas all viruses from the Id2 subgroup were isolated after 2003.
\end{abstract}

KEY WORDS: Rhabdovirus · Spring viraemia of carp virus · Sequence analysis · Genogroups · Glycoprotein gene $\cdot$ Phylogenetic analysis

\section{INTRODUCTION}

Spring viraemia of carp virus (SVCV) is the causative agent of a severe haemorrhagic and contagious disease in several carp species. Natural occurrences have also been reported in other members of the cyprinid family and one non-cyprinid species. Additional species were susceptible to SVCV infection in experimental studies (Haenen \& Davidse 1993, Ahne et al. 2002, Sanders et al. 2003). SVCV can cause high mortality in young fish during outbreaks and substantial economic losses for carp farmers (Ahne et al. 2002).

SVCV was first isolated in the early 1970s in Yugoslavia and has until now been reported in most European countries, in the Middle East, USA, China, Canada and Brazil (Fijan et al. 1971, Bucke \& Finlay 1979, Ahne et al. 2002, Goodwin 2002, Dikkeboom et al. 2004, Liu et al. 2004, Garver et al. 2007, Warg et al. 2007).
SVCV is a member of the genus Vesiculovirus within the family Rhabdoviridae. Phylogenetic analysis based on a nucleotide sequence of the region of the glycoprotein gene (G gene) of SVCV has been used to differentiate isolates into 4 genogroups (Ia to Id). These genogroups tend to be differentiated geographically. Genogroup Ia contains viruses originating from Asia, genogroups Ib and Ic those from Moldova, Ukraine and Russia, and genogroup Id those from Europe, UK and some parts of the former USSR (Koutna et al. 2003, Stone et al. 2003, Sheppard et al. 2007). Five US isolates and one Canadian isolate were also grouped in genogroup Ia (Garver et al. 2007, Warg et al. 2007). Because several isolates from areas within the former USSR clustered with the European genogroup Id (Stone et al. 2003), and several isolates from the UK and Italy clustered with the Asian genogroup Ia (Miller et al. 2007), further investigations of different SVCV isolates from all over the world are necessary to com- 
plete the sub-grouping of SVCV isolates. Therefore, the purpose of this study was to determine genetic relatedness of Austrian SVCV isolates.

The G protein forms trimeric peplomers or spikes on the virus surface that bind to cellular receptors and trigger viral endocytosis (Ahne et al. 2002). It carries neutralizing epitopes and is a potential target for the development of DNA vaccines (Kim et al. 2000, Kanellos et al. 2006). As a consequence, knowledge about the sequence of the $G$ protein of the circulating European SVCV may also be important for the development of vaccines against SVCV.

For hydrogeographic and climatic reasons carp farming in Austria is confined to the eastern part of the country, where 2 significantly different regions represent the main areas of production comprising the cool region in northern Lower Austria and the warm hills in the southeast of Styria. The different environmental conditions result in considerably different rates of fish growth. Empirical observations indicate that SVCV infections in carps from the northern region show more apparent signs of the disease and higher mortality rates in contrast to carps localised in the southern part, which rarely die from the infection. In the present study we also investigated whether different types of SVCV occur in these 2 geographic regions.

We determined the nucleotide sequence and predicted amino acid sequence of a portion of the G gene of 22 Austrian SVCV isolates collected between 1994 and 2007 and compared them with each other and to the American Type Culture Collection (ATCC) reference strain of SVCV VR-1390 (GenBank NC_002803) (Bjorklund et al. 1996). We also conducted phylogenetic analyses of Austrian SVCV isolates and representative isolates of the 4 genogroups that represent the geographic and genetic diversity of SVCV.

\section{MATERIALS AND METHODS}

Some characteristics of the SVCV isolates used in the study are listed in Table 1. Most samples were prepared from fish that had perished or were killed when found in moribund condition. However, some sam-

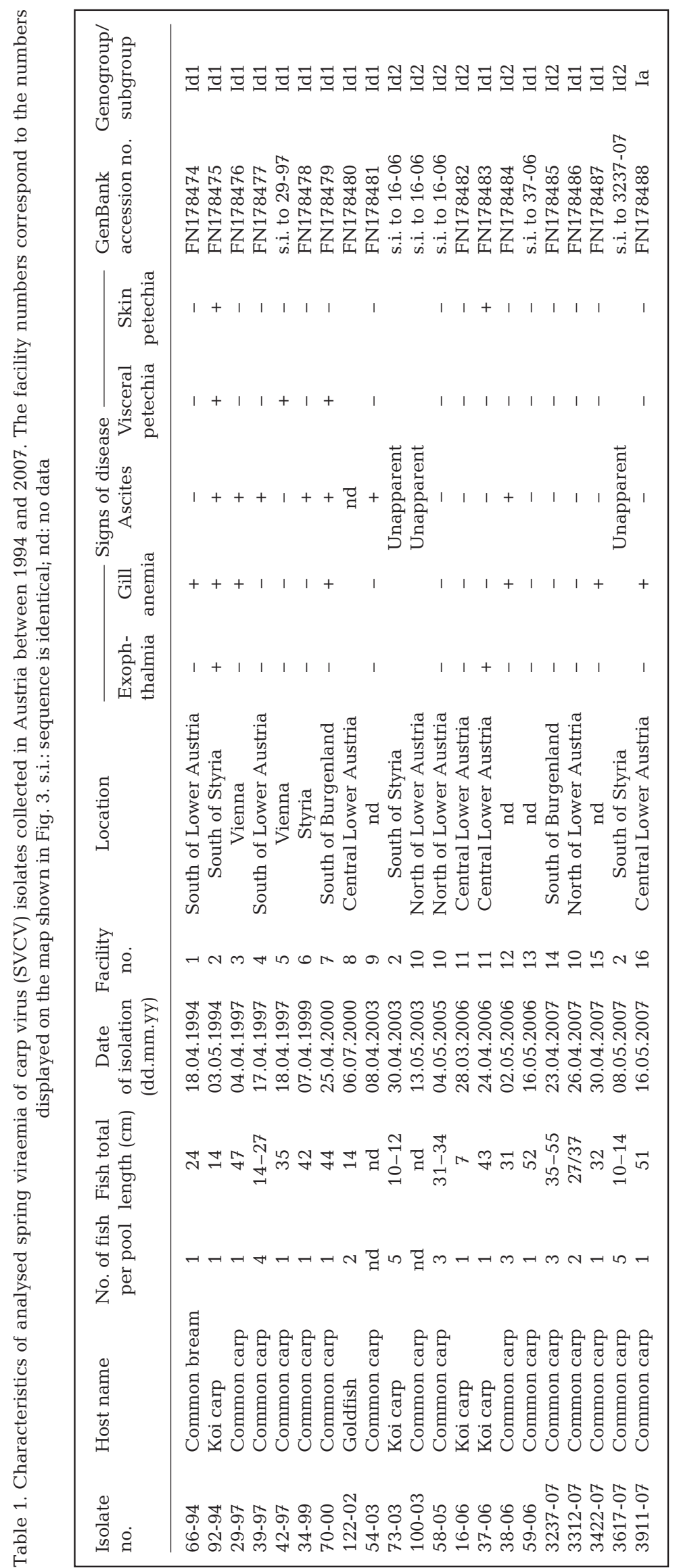


ples were prepared from clinically healthy fish and the sampling was conducted as part of a routine survey. Most samples were prepared from a single fish. In cases where organs from more then one fish were pooled, all fish displayed similar clinical signs of disease or the fish were clinically healthy.

The original fish samples consisted of organ pools comprising spleens, head kidneys and hearts of 1 to 5 individuals. The organ pools were homogenized in MEM containing $2 \%$ fetal bovine serum and $0.1 \%$ gentamycin (1:10 v/v dilution). Following 15 min centrifugation at $2000 \times g$ the supernatant was filtered through syringe filters with $0.45 \mu \mathrm{m}$ pore size. Organ homogenates were used directly for RNA isolation and for inoculation of confluent monolayers of epithelioma papulosum cyprini (EPC) cells at final dilutions of 1:100 and 1:1000. The cells were incubated at $20^{\circ} \mathrm{C}$. After 4 to $8 \mathrm{~d}$ the supernatants were passed onto fresh monolayers for at least $1 \mathrm{wk}$ of further incubation. The supernatants of obviously infected cell monolayers showing cytopathic effect (CPE) were also used for RNA isolation. Total RNA was isolated from $250 \mu \mathrm{l}$ of tissue homogenates or cell culture supernatants using the RNeasy Mini Kit (Qiagen) according to manufacturer's instructions. RNA was eluted with $35 \mu$ l RNasefree water.

Synthesis of cDNA and subsequent PCR were carried out in a single tube using One Step RT-PCR Kit (Qiagen). Each reaction contained $1 \mu \mathrm{M}$ (final concentration) each of SVCV F1 and SVCV R2 primers (Stone et al. 2003) and $5 \mu \mathrm{l}$ volume of RNA extract (corresponding to $20 \%$ of the total reaction volume). Additionally, $40 \mathrm{U}$ of RNaseOUT RNase inhibitor (Invitrogen $\mathrm{GmbH}$ ) were used. Reverse transcription ( $30 \mathrm{~min}$ at $50^{\circ} \mathrm{C}$ and $15 \mathrm{~min}$ at $95^{\circ} \mathrm{C}$ ) was followed by 35 amplification cycles of $1 \mathrm{~min}$ at $95^{\circ} \mathrm{C}, 1 \mathrm{~min}$ at $55^{\circ} \mathrm{C}$ and $1 \mathrm{~min}$ at $72^{\circ} \mathrm{C}$ per cycle, and a final extension step for $10 \mathrm{~min}$ at $72^{\circ} \mathrm{C}$. After gel electrophoresis PCR products were extracted from the gel with the QIAquick Gel Extraction Kit (Qiagen) according to the manufacturer's recommendations. Eluted PCR products were directly sequenced in both directions using SVCV F1 and SVCV R2 primers. Sequencing services were provided by MWG-Biotech, Ebersberg, Germany. Each PCR product was sequenced in both directions.

The nucleotide sequences were identified as SVCV sequences by basic local alignment search tool (BLAST) search. The oligonucleotide primer pairs used in this study amplified a $714 \mathrm{bp}$ region of the G gene of SVCV (Stone et al. 2003). For sequence analysis primer binding sites were excluded from analysis and a $630 \mathrm{bp}$ fragment was analysed. The sequences of the $630 \mathrm{bp}$ fragment of G gene of analysed Austrian SVCV isolates (corresponding to 3388-4017 bp of GenBank sequence NC_002803) were deposited in the GenBank and accession numbers are listed in Table 1. The sequences were compared with each other and to the already published sequence of VR-1390 (GenBank NC_002803) (Bjorklund et al. 1996). Assembly and analysis of sequences as well as the nucleotide and amino acid alignments were performed using Accelrys Gene v. 2.5 (Accelrys), Lasergene (DNASTAR) and BioEdit (Tom Hall, Ibis Biosciences) software.

For phylogenetic analysis a $630 \mathrm{bp}$ region (corresponding to 3388-4017 bp of the GenBank sequence NC_002803) and a $426 \mathrm{bp}$ region (corresponding to 3522-3947 bp of the GenBank sequence NC_002803) of the $\mathrm{G}$ gene were used. Only unique sequence types were used. Other sequences used were already published sequences of SVCV isolates, mainly originating from Europe and USA (Stone et al. 2003, Miller et al. 2007). Phylogenetic analysis was performed using Accelrys Gene v. 2.5 (Accelrys) and Lasergene (DNASTAR) software. Phylogenetic trees were generated by the Neighbor-Joining (NJ) method as implemented in Lasergene (DNASTAR) software. Robustness of the tree was determined by bootstrapping of multiplesequence alignments (1000 sets). Phylogenetic trees were also generated by the NJ method on uncorrected p-distances on 1000 bootstrapped data sets and values of $>70 \%$ were shown on the tree as branches when Accelrys Gene v. 2.5 (Accelrys) was used.

\section{RESULTS}

Sequence analyses revealed that nucleotide sequence identities of the analysed portion of the $\mathrm{G}$ gene of 22 Austrian isolates ranged between 90.3 and $100 \%$ (0 to 61 nucleotide substitutions of $630 \mathrm{bp}$ ) with each other and between 91.1 and $99.4 \%$ (4 to 56 nucleotide substitutions of $630 \mathrm{bp}$ ) with VR-1390 (GenBank NC_002803) (Bjorklund et al. 1996). Nucleotide sequence differences were observed throughout the $630 \mathrm{bp}$ region analysed (Fig. 1). For the investigated part of the G protein, predicted amino acid sequence identities among the Austrian isolates ranged between 90.0 and $100 \%$ ( 0 to 21 amino acid substitutions of 210), and between 91.4 and $100 \%$ (0 to 18 amino acid substitutions of 210) with VR-1390 (data not shown).

Phylogenetic analysis based on the $630 \mathrm{bp}$ region of the G gene was conducted. Austrian isolates and representative isolates of the genogroups Id and Ia whose sequences were available in GenBank were used. The phylogenetic analysis revealed that all Austrian isolates except one (3911-07) belonged to the SVCV Id genogroup (Fig. 2a). Only one isolate (3911-07) belonged to the SVCV Ia genogroup. Remarkably, 3 clusters (designated Id1, Id2 and Id3) were identified 


NC_002803
$66-94$
$92-94$
$29-97 \quad(2$ ISOLATES $)$
$39-97$
$34-99$
$70-00$
$122-02$
$54-03$
$16-06 \quad(5$ ISOLATES $)$
$37-06 \quad(2$ ISOLATES $)$
$38-06$
$3237-07$ (2 ISOLATES)
$3312-07$
$3422-07$
$3911-07$

NC_002803
$66-94$
$92-94$
$29-97 \quad(2$ ISOLATES $)$
$39-97$
$34-99$
$70-00$
$122-02$
$54-03$
$16-06 \quad(5$ ISOLATES $)$
$37-06 \quad(2$ ISOLATES $)$
$38-06$
$3237-07$ (2 ISOLATES)
$3312-07$
$3422-07$
$3911-07$

NC_ 002803

$66-94$

$92-94$

29-97 (2 ISOLATES)

39-97

$34-99$

$70-00$

$122-02$

$54-03$

16-06 (5 ISOLATES)

37-06 (2 ISOLATES)

$38-06$

3237-07 (2 ISOLATES)

3312-07

3422-07

3911-07

NC_002803
$66-94$
$92-94$
$29-97 \quad(2$ ISOLATES $)$
$39-97$
$34-99$
$70-00$
$122-02$
$54-03$
$16-06 \quad(5$ ISOLATES $)$
$37-06 \quad(2$ ISOLATES $)$
$38-06$
$3237-07$ (2 ISOLATES)
$3312-07$
$3422-07$
$3911-07$
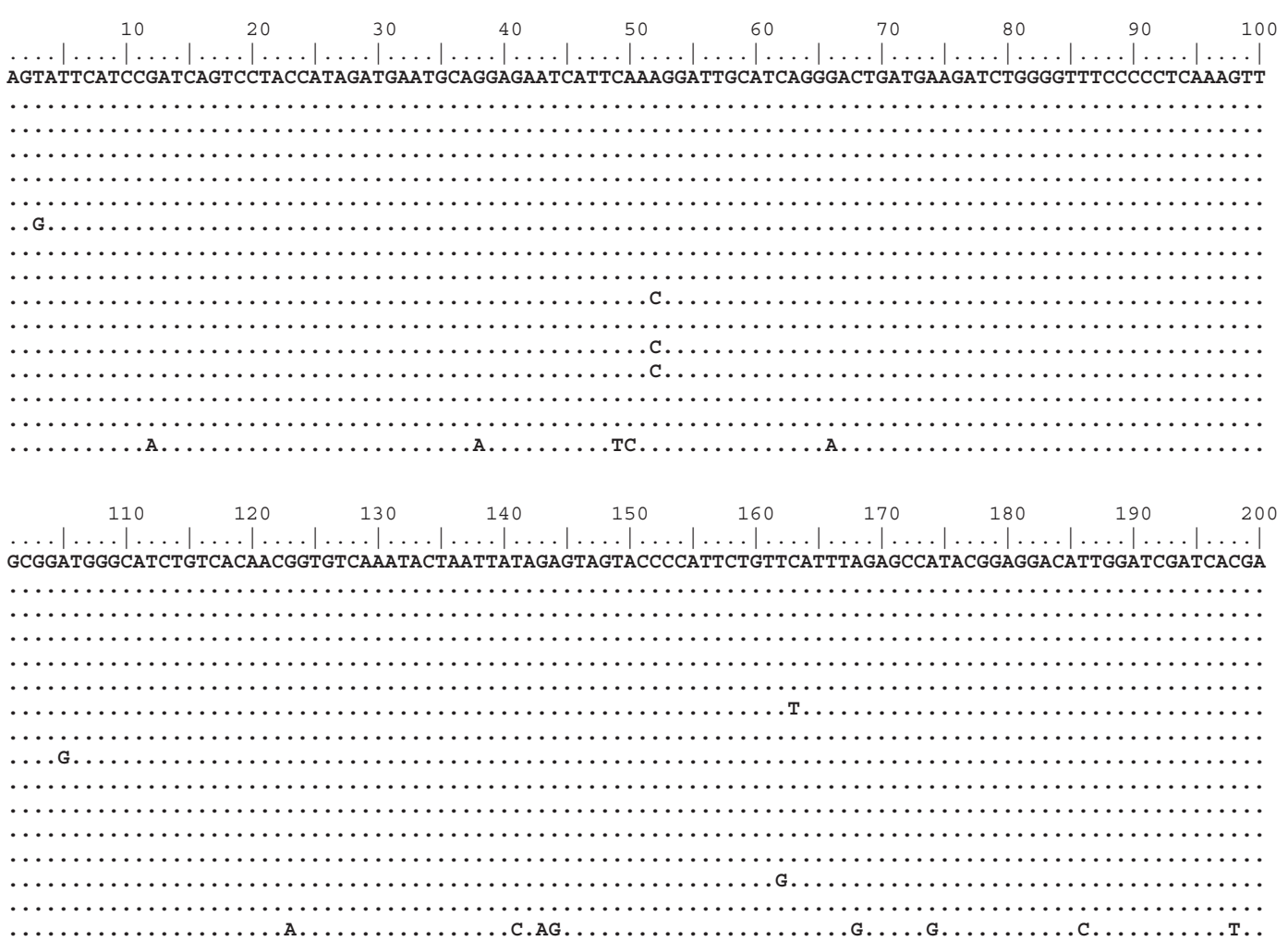

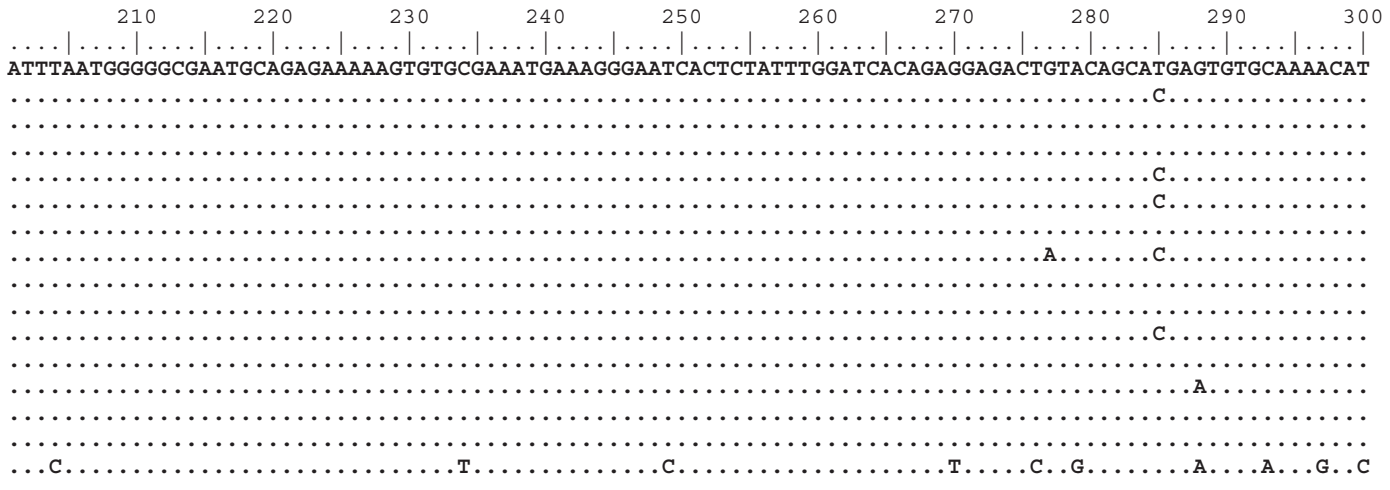

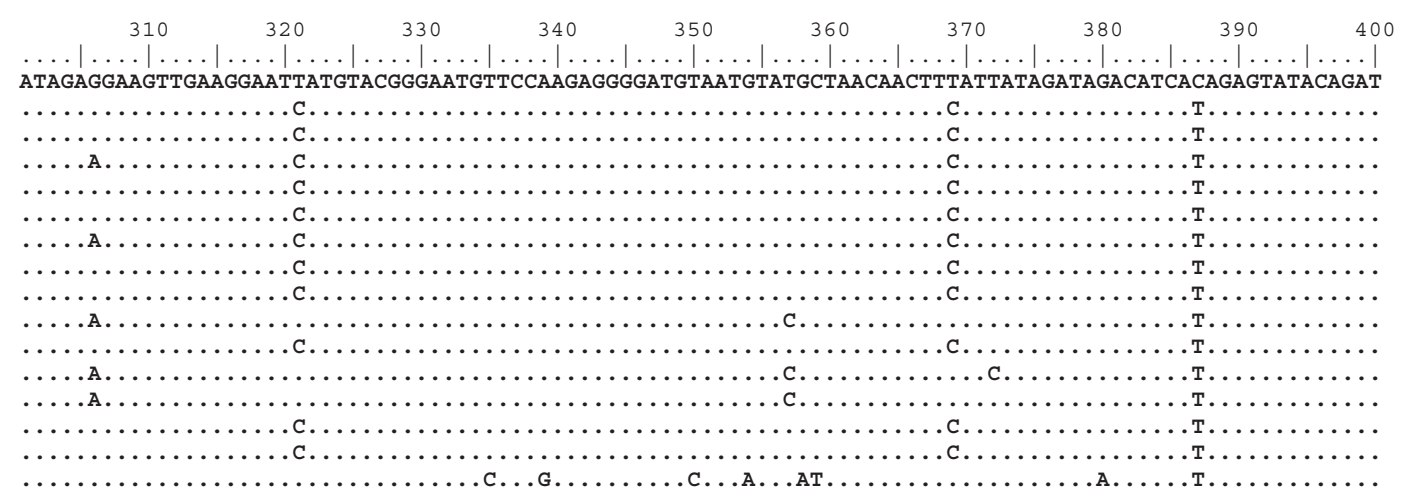

Fig. 1. Comparison of the nucleotide sequences of the Austrian isolates of SVCV with the American Type Culture Collection (ATCC) reference strain of SVCV VR-1390 (GenBank NC_002803) (Bjorklund et al. 1996). NC_002803 is shown at the top and only differences are indicated in other SVCV isolates. Only the unique sequence types are included and the numbers of isolates having the sequence are shown in round brackets 


NC_002803
$66-94$
$92-94$
$29-97 \quad(2$ ISOLATES $)$
$39-97$
$34-99$
$70-00$
$122-02$
$54-03$
$16-06 \quad(5$ ISOLATES $)$
$37-06$ (2 ISOLATES)
$38-06$
$3237-07$ (2 ISOLATES)
$3312-07$
$3422-07$
$3911-07$

NC_002803
$66-94$
$92-94$
$29-97 \quad(2$ ISOLATES $)$
$39-97$
$34-99$
$70-00$
$122-02$
$54-03$
$16-06 \quad(5$ ISOLATES $)$
$37-06 \quad(2$ ISOLATES $)$
$38-06$
$3237-07$ (2 ISOLATES)
$3312-07$
$3422-07$
$3911-07$

NC_002803
$66-94$
$92-94$
$29-97 \quad(2$ ISOLATES $)$
$39-97$
$34-99$
$70-00$
$122-02$
$54-03$
$16-06 \quad(5$ ISOLATES $)$
$37-06 \quad(2$ ISOLATES $)$
$38-06$
$3237-07$ (2 ISOLATES $)$
$3312-07$
$3422-07$
$3911-07$
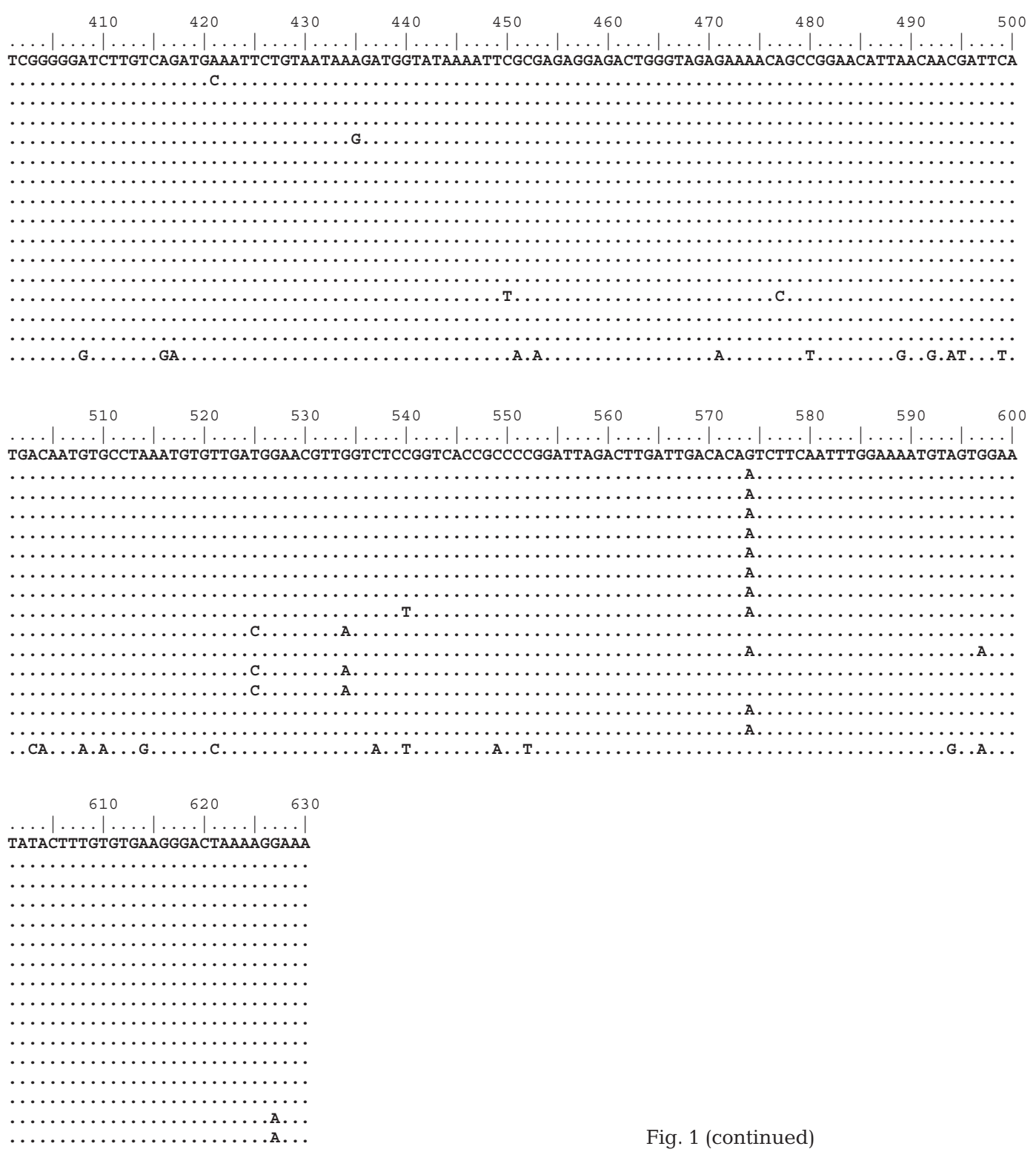

Fig. 1 (continued) within genogroup Id. The same division of SVCV isolates was observed when using Accelrys Gene v. 2.5 for generating the phylogenetic tree and the existence of 3 clusters within genogroup Id (Id1, Id2 and Id3) was supported by bootstrap values of 73,97 and $81 \%$, respectively (Fig. 2b).

All Austrian isolates belonging to genogroup Id were grouped into clusters Id1 or Id2. Nucleotide sequence identities between them ranged between 97.9 and $100 \%$ (based on $630 \mathrm{bp}$ region) and their predicted amino acid sequence identities ranged between 98.6 and $100 \%$ (data not shown). The BLAST search showed that Austrian isolates belonging to genogroup Id were most closely related to VR-1390 (data not shown).
Only one common nucleotide difference between VR-1390 and the Austrian isolates $(\mathrm{C} \rightarrow \mathrm{T}$ at position 387) occurred in all Austrian isolates within genogroup Id (Fig. 1). Five additional nucleotide differences $(A \rightarrow C$ at position $52, G \rightarrow A$ at position 306, $\mathrm{T} \rightarrow \mathrm{C}$ at position $357, \mathrm{~T} \rightarrow \mathrm{C}$ at position 525 and $\mathrm{G} \rightarrow \mathrm{A}$ at position 534) were shared between all members of the Id2 cluster. Three more nucleotide differences $(\mathrm{G} \rightarrow \mathrm{A}$ at position $288, \mathrm{C} \rightarrow \mathrm{T}$ at position 450 and $\mathrm{A} \rightarrow \mathrm{C}$ at position 477) occurred in isolates 3237-07 and 3617-07. Within cluster Id1, 3 nucleotide differences $(\mathrm{T} \rightarrow \mathrm{C}$ at position $321, \mathrm{~T} \rightarrow \mathrm{C}$ at position 369 and $\mathrm{G} \rightarrow \mathrm{A}$ at position 574) were noticed in all isolates. One nucleotide difference $(\mathrm{T} \rightarrow \mathrm{C}$ at position 285) was present in 6 isolates of the Id1 cluster. Nucleotide 
a

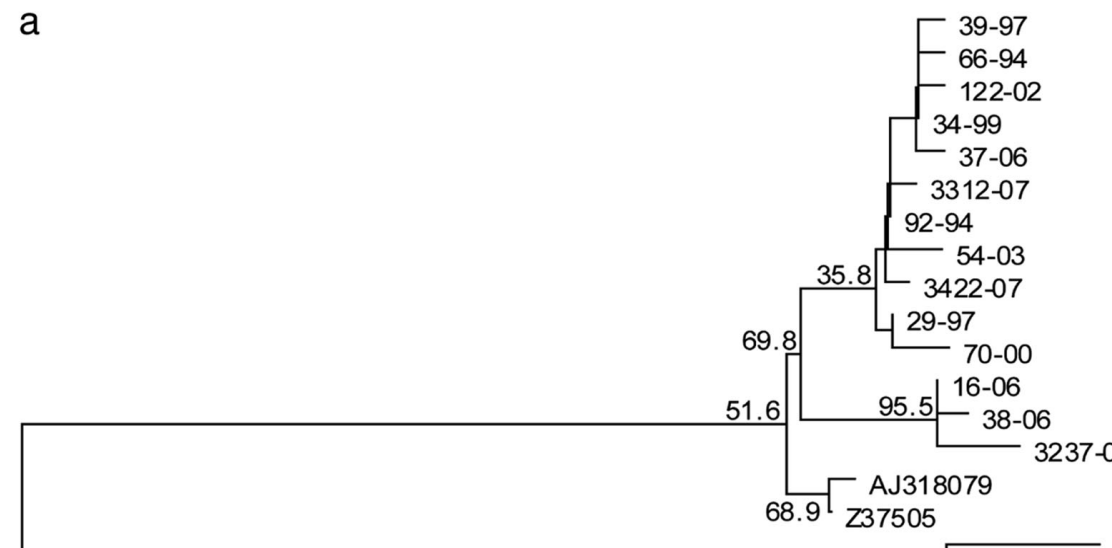

Id1

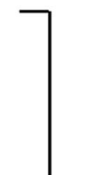

AY 842487

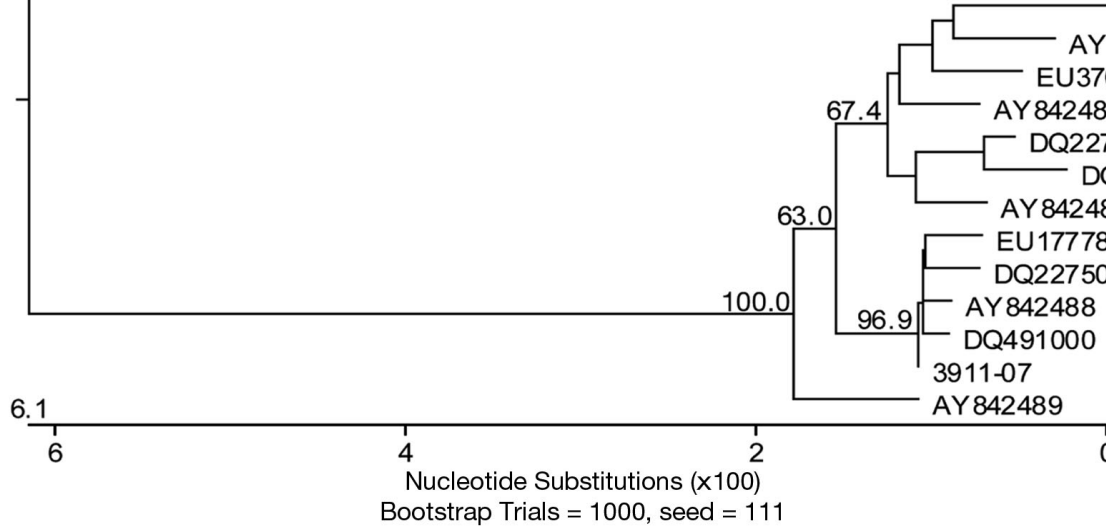

b

Bootstrap Trials $=1000$, seed $=111$

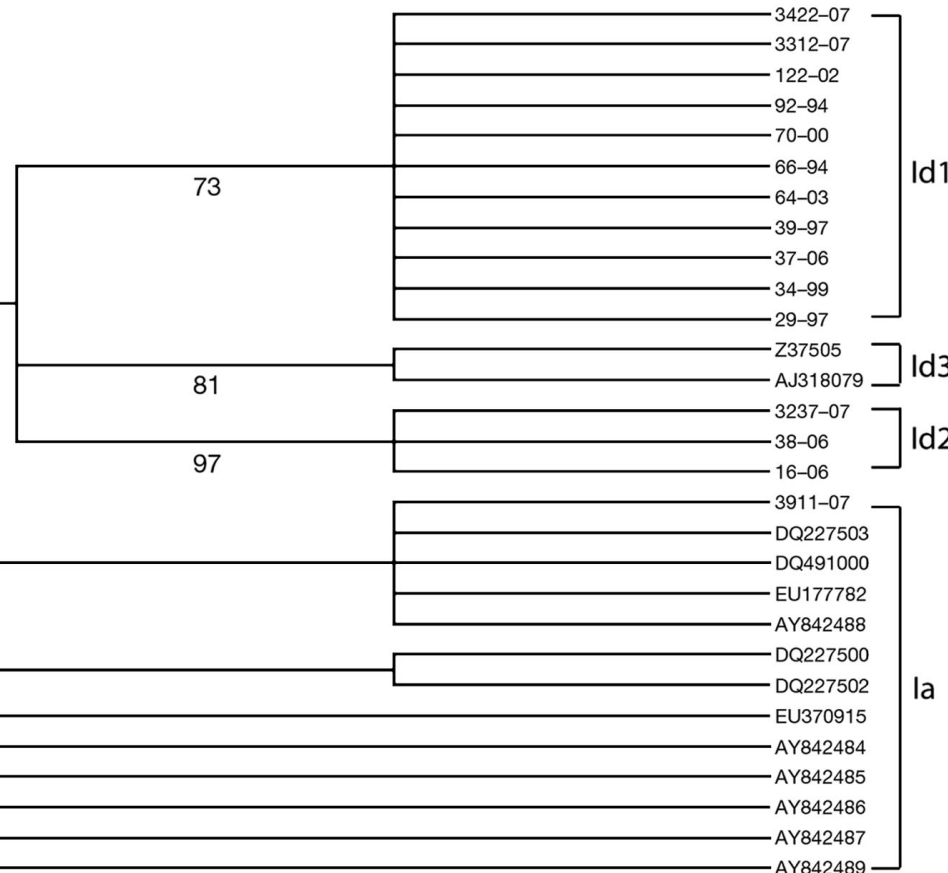

Fig. 2. Phylogenetic trees of Austrian SVCV isolates and representatives of SVCV genogroups based on (a, b) 630 bp and (c) $426 \mathrm{bp}$ region of the $\mathrm{G}$ gene. The sequences used were already published sequences of SVCV isolates, mainly originating from Europe and the USA (Stone et al. 2003, Miller et al. 2007). (a) and (c) The Neighbor-Joining (NJ) trees were generated using the Lasergene (DNASTAR) software. The length of each pair of branches represents the distance between sequence pairs, whilst the units at the bottom of the trees indicate the number of substitution events. Bootstrap values are indicated for the major nodes. (b) Phylogenetic tree was generated by the NJ method on uncorrected p-distances on 1000 bootstrapped data sets, and values of $>70 \%$ were shown on the tree as branches when Accelrys Gene v. 2.5 (Accelrys) was used 


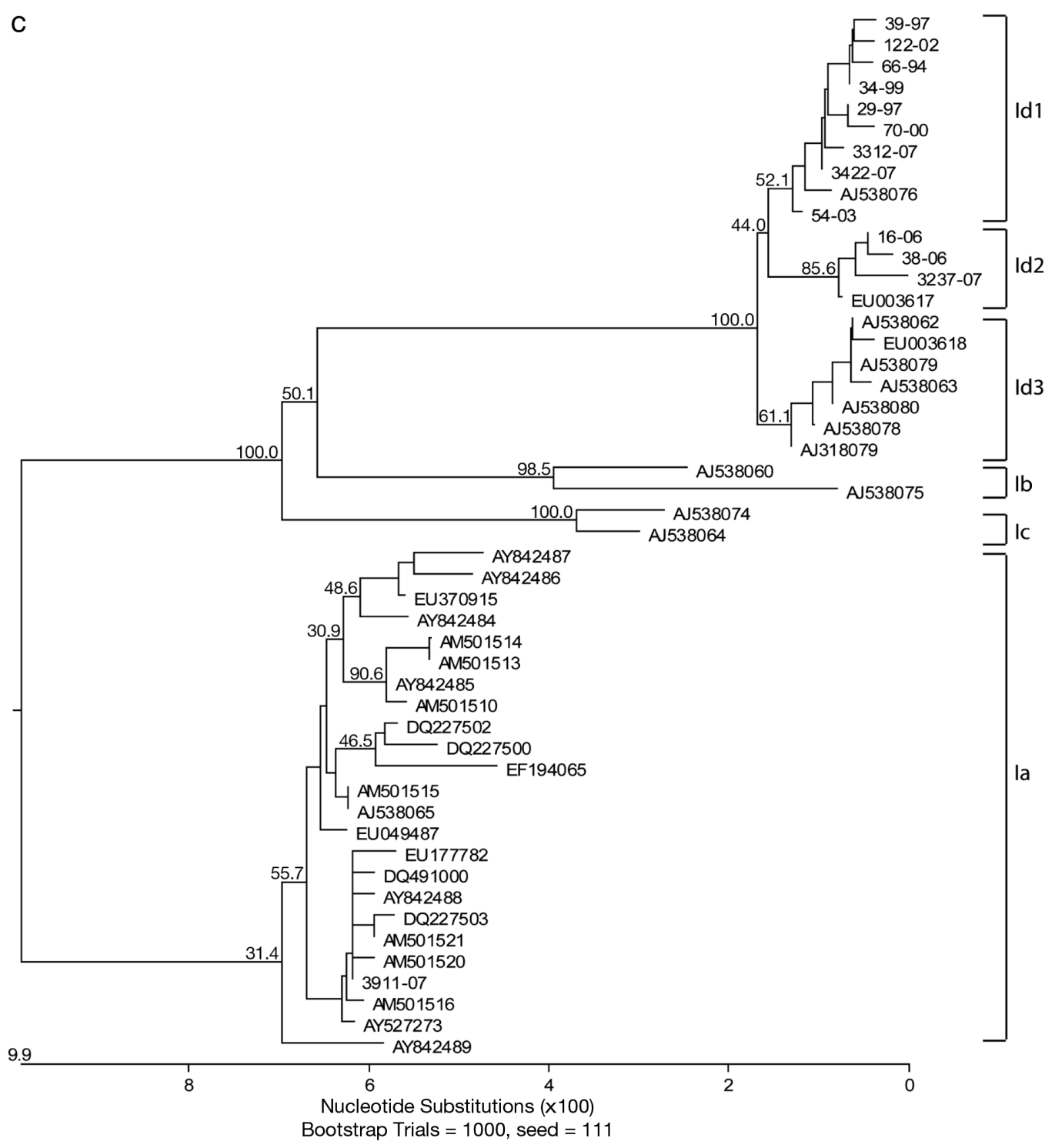

Fig. 2 (continued)

difference $\mathrm{G} \rightarrow \mathrm{A}$ at position 306 was present both in members of Id1 and Id2 clusters.

One Austrian SVCV isolate (3911-07), however, belongs to genogroup Ia and was isolated from fish sampled in 2007. Focusing on genogroup Ia, isolate 3911-07 showed in the BLAST search $100 \%$ nucleotide identity with a US isolate from Missouri (GenBank DQ227504) (Warg et al. 2007) (data not shown).

No correlation was observed between the nucleotide sequence differences and the host species (Table 1). Viruses showing high percentage of nucleotide sequence identities between each other were isolated from both common carp Cyprinus carpio and koi (isolates 58-05, 100-03, 16-06, 59-06 and 73-03 were $100 \%$ identical and isolates 3312-07, 3422-07, 92-94 and 5403 were $99.5 \%$ to $99.8 \%$ identical) and common carp, koi, common bream Abramis brama and goldfish Carassius auratus (isolates 66-94, 122-00, 39-97, 34-99, 825-07 and 37-06 were 99.7 to $100 \%$ identical).

In our study nucleotide differences could also not be linked to clinical signs of disease (Table 1). Viruses with a very high percentage of nucleotide sequence identities $(99.8 \%)$ were isolated from fish showing clear signs of infection (38-06) and only moderate or nonspecific signs of disease (58-05, 100-03, 16-06, 5906 and 73-03). Two other virus isolates (37-06 and 82507) were isolated from fish with clear signs of disease and showed 99.7 to $99.8 \%$ sequence identity with viruses (66-94, 39-97 and 34-99) isolated from fish showing only moderate or nonspecific signs of disease. In addition, viruses associated with clear signs of disease were grouped in different clusters based on the 
nucleotide sequences, and the same was found for some unapparent cases. For example, isolate 38-06 was isolated from fish showing clear signs of infection and belongs to cluster Id2. The same was noticed for isolates 70-00, 29-97, 825-07, 37-06 and 92-94 that belong to cluster Id1. Similarly, isolates 58-05, 100-03, 16-06, 59-06, 73-03, 3237-07 and 3617-07 were isolated from fish showing only moderate or nonspecific signs of disease and belong to cluster Id2, while other isolates associated with moderate or nonspecific signs of disease $(66-94,39-97,34-99,3312-07$ and 54-03) belong to cluster Id1. Interestingly, most fish exhibiting signs of disease like exophthalmia, gill anemia, ascites and visceral petechia harboured Id1 viruses. On the other hand, all isolates from unapparent cases of infection belonged to Id2 subgroup.

In some cases it appears that area-dependent nucleotide sequence identities were observed. Two isolates from the Viennese area (42-97 and 29-97) were identical to each other. Also, 2 identical isolates (323707 and 3617-07) were isolated from geographically close regions (Table 1, Fig. 3). However, in general, the genetic clustering could not be linked to different regions in Austria (northern Lower Austria and southeast of Styria). For example, isolates 58-05 and 100-03 isolated in northern Lower Austria, 16-06 isolated in central Lower Austria and 73-03 isolated in southern Styria are $100 \%$ identical. Also, 2 isolates (92-94 and 73-03) from the same farm belong to 2 different clusters (Id1 and Id2, respectively) and the differences of nucleotide sequences suggest recent introduction of a new virus into this farm. At the same farm, isolate

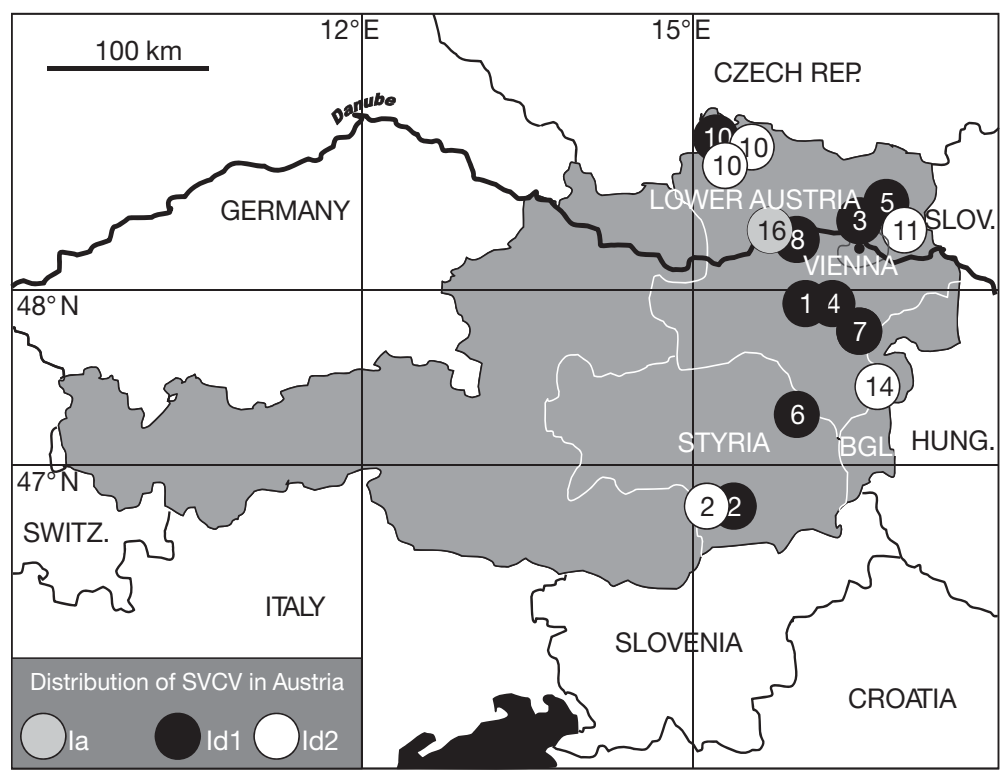

Fig. 3. Distribution of SVCV isolates in Austria. Facility numbers are shown and genogroup/subgenogroups are indicated by different shades of grey. Id1: black; Id2: white; Ia: grey
3617-07 was isolated in 2007 and also belongs to cluster Id2. A similar case was noticed on another farm, where 2 isolates (16-06 and 37-06) were sampled in a short time-frame and found to belong to 2 different clusters (Id2 and Id1, respectively). Based on the nucleotide sequences, introduction of a new virus is suggested. At the same farm, isolate 825-07 was isolated in 2007 and was identical to isolate 37-06. Multiple introductions of the SVCV also existed at the third farm. Isolates sampled in 2003 and 2005 (100-03 and $58-05$, respectively) were $100 \%$ identical and belong to cluster Id2. Nevertheless, isolate 3312-07 sampled at the same farm in 2007 belongs to cluster Id 1 and based on the differences of nucleotide sequences probably represents a recent introduction of a new virus.

Time-dependent division of Austrian SVCV isolates could be observed. All isolates sampled before 2003 belong to cluster Id1. Isolates sampled after 2003 belong to both Id1 and Id2 clusters (Table 1).

In attempt to include as many sequences as possible in our phylogenetic analysis and to use available sequences from GenBank from other genogroups, we conducted a phylogenetic analysis of 48 unique SVCV sequences based on the 426 bp region of the $\mathrm{G}$ gene (Fig. 2c) (Miller et al. 2007). Clustering of isolates was consistent with the analysis of $630 \mathrm{bp}$ region (Fig. 2a,b). Again, 3 clusters (designated Id1, Id2 and Id3) were identified within genogroup Id. The same division of SVCV isolates was observed when using Accelrys Gene v. 2.5 for generating the phylogenetic tree and the existence of 2 subgroups within genogroup Id (Id2 and Id3) was supported by bootstrap values of 89 and $73 \%$, respectively (data not shown).

\section{DISCUSSION}

In our study, no correlation was observed between the nucleotide sequence differences among different Austrian SVCV isolates and the host species. Stone et al. (2003) also did not observe a correlation between the genogroups and the host species. Similarly, Hoffman et al. found no correlation between amino acid exchanges in the P gene and the host species (Hoffmann et al. 2005). However, Warg et al. (2007) reported a higher percentage of nucleotide sequence identity between isolates from common carp in comparison with isolates from koi and vice versa, but the reason for this result could be separate introductions of SVCV into wild fish populations and hobby koi in the USA. 
Also, nucleotide differences could not be clearly linked to certain clinical signs of disease (Table 1). Although, in some cases clinical signs of disease were stronger than in others, we could not exclude that water temperature, population density, stress factors, age, physiological state or status of innate immunity were reasons for these differences. In addition, viruses associated with clear signs were grouped into different clusters based on the nucleotide sequences, and the same was found for some unapparent cases. Moreover, viruses with a very high percentage of nucleotide sequence identities were isolated from fish showing either clear signs of infection or only moderate or nonspecific signs of disease. In these cases environmental factors and not viral genetics seem to influence the pathology. Nevertheless, to estimate the influence of viral genetics on pathology and mortality experimental infections with different SVCV isolates would be necessary.

Area-dependent genetic clustering of Austrian SVCV isolates was not observed. In addition, multiple introductions of SVCV were shown to exist at more than one site. It is, however, difficult to identify sources of infection and follow the transmission and introductions of the virus because of the complexity of fish farming and rapid and constant exchange of fish between different fish farms.

Time-dependent division of Austrian SVCV isolates could be observed. Viruses from the Id1 cluster were mainly sampled in Austria until 2003. No isolates from the cluster Id2 were isolated before 2003. After 2003, all isolates from the cluster Id 2 and also several isolates belonging to cluster Id1 were sampled. The question remains unanswered which mechanisms may have contributed to this shift. Alternatively, the viruses of Id2 subgroup have been present and undetected in Austria until the year 2003.

The phylogenetic analyses revealed that all Austrian isolates except one belonged to the SVCV Id genogroup, emphasizing the genetic relatedness of Austrian SVCV isolates to the other European members of this virus species. One Austrian SVCV isolate (3911-07), however, belongs to the genogroup Ia and was isolated from fish sampled in 2007. Genogroup Ia contains isolates from Asia, Canada, the USA, the UK and Italy (Stone et al. 2003, Garver et al. 2007, Miller et al. 2007, Warg et al. 2007). Although isolate 3911-07 could not be traced back to its origin, it showed $100 \%$ nucleotide identity with the isolate from Missouri. From the data it can be inferred that isolate 3911-07 and the Missouri isolate share a common ancestor. It was postulated that isolates from North America and the UK belonging to genogroup Ia were introduced from Asia (Miller et al. 2007). However, it remains unclear whether the virus isolated in Austria was introduced directly from Asia or entered the country via a third pathway.

Phylogenetic analyses of unique SVCV sequences based on regions of $\mathrm{G}$ gene of different length indicate the existence of 3 clusters (Id1, Id2 and Id3) within genogroup Id. The same division of SVCV isolates was observed when using Accelrys Gene v. 2.5 for generating the phylogenetic tree and the existence of 2 subgroups within genogroup Id (Id2 and Id3) was supported by high bootstrap values of $>70 \%$. Recently, 2 subgroups within the genogroup Id with high bootstrap values were suggested (Miller et al. 2007). However, the subgroups in that study formed only one cluster. The reason for this is probably the limited number of investigated European sequences, which originated mostly from the UK and Germany. Moreover, in contrast to the study of Miller et al. (2007), which was based on P gene sequences, our study was based on $\mathrm{G}$ gene sequences. This could also be the reason for the noted differences, but it supports the likelihood of the existence of different subgroups within the genogroup Id. Phylogenetic analysis of North American and UK isolates based on $\mathrm{P}$ gene sequences revealed 2 subgroups within genogroup Ia, supported by bootstrap values of $>72 \%$ (Miller et al. 2007). Between the members of these 2 subgroups a high degree of sequence divergence was noticed (0 to 21 nucleotide substitutions of $898 \mathrm{bp}$ for the $\mathrm{P}$ gene and 0 to 11 nucleotide substitutions of $426 \mathrm{bp}$ for the $\mathrm{G}$ gene). In our study, between the analysed members of subgroups Id 2 and Id3, 0 to 12 nucleotide substitutions for the same region (426 bp) of the $\mathrm{G}$ gene were detected. In addition, clustering of isolates within Ia genogroup in our study corresponded to subgroups Iai and Iaii suggested by Miller et al. (2007). This designation into subgroups offers the potential for novel and additional information in phylogenetic analysis of SVCV molecular epidemiology.

The evolution and further epidemiological analysis of European SVCV may also be important for any future vaccine developments against SVCV. In this context only limited data are available. The first reported DNA vaccine contained the G gene of the reference strain of SVCV VR-1390 (genogroup Id) and it was not tested to determine whether fish would be protected using members of other SVCV genogroups as a challenge (Kanellos et al. 2006). In our study, divergence of $10.6 \%$ at the nucleotide and $12.4 \%$ at the amino acid G gene sequence levels between analysed members of different SVCV genogroups were observed (based on $630 \mathrm{bp}$ region). This could be important when trying to adopt a vaccination strategy that would protect fish against circulating European SVCVs. 
Acknowledgements. The authors thank the Austrian Federal Ministry of Health, Family and Youth for financial support.

\section{LITERATURE CITED}

Ahne W, Bjorklund HV, Essbauer S, Fijan N, Kurath G, Winton JR (2002) Spring viremia of carp (SVC). Dis Aquat Org 52:261-272

Bjorklund HV, Higman KH, Kurath G (1996) The glycoprotein genes and gene junctions of the fish rhabdoviruses spring viremia of carp virus and hirame rhabdovirus: analysis of relationships with other rhabdoviruses. Virus Res 42: 65-80

Bucke D, Finlay J (1979) Identification of spring iremia in carp (Cyprinus carpio L) in Great Britain. Vet Rec 104:69-71

Dikkeboom AL, Radi C, Toohey-Kurth K, Marcquenski S and others (2004) First report of spring viremia of carp virus (SVCV) in wild common carp in North America. J Aquat Anim Health 16:169-178

Fijan N, Petrinec Z, Sulimanovic D, Zwillenberg LO (1971) Isolation of the viral causative agent from the acute form of infectious dropsy of carp. Vet Arh 41:125-138

Garver KA, Dwilow AG, Richard J, Booth TF, Beniac DR, Souter BW (2007) First detection and confirmation of spring viraemia of carp virus in common carp, Cyprinus carpio L., from Hamilton Harbour, Lake Ontario, Canada. J Fish Dis 30:665-671

Goodwin AE (2002) First report of spring viremia of carp virus (SVCV) in North America. J Aquat Anim Health 14: 161-164

Haenen OLM, Davidse A (1993) Comparative pathogenicity of two strains of pike fry rhabdovirus and spring viremia of carp virus for young roach, common carp, grass carp and rainbow trout. Dis Aquat Org 15:87-92

Hoffmann B, Beer M, Schutze H, Mettenleiter TC (2005) Fish rhabdoviruses: molecular epidemiology and evolution. Curr Top Microbiol Immunol 292:81-117

Editorial responsibility: Stewart Johnson, Nanaimo, British Columbia, Canada
Kanellos T, Sylvester ID, D'Mello F, Howard CR and others (2006) DNA vaccination can protect Cyprinus carpio against spring viraemia of carp virus. Vaccine 24: 4927-4933

Kim CH, Johnson MC, Drennan JD, Simon BE, Thomann E, Leong JAC (2000) DNA vaccines encoding viral glycoproteins induce nonspecific immunity and Mx protein synthesis in fish. J Virol 74:7048-7054

> Koutna M, Vesely T, Psikal I, Hulova J (2003) Identification of spring viraemia of carp virus (SVCV) by combined RT-PCR and nested PCR. Dis Aquat Org 55:229-235

Liu H, Gao L, Shi X, Gu T, Jiang Y, Chen H (2004) Isolation of spring viraemia of carp virus (SVCV) from cultured koi (Cyprinus carpio koi) and common carp (C.carpio carpio) in PR China. Bull Eur Assoc Fish Pathol 24: 194-202

Miller O, Fuller FJ, Gebreyes WA, Lewbart GA and others (2007) Phylogenetic analysis of spring virema of carp virus reveals distinct subgroups with common origins for recent isolates in North America and the UK. Dis Aquat Org 76: 193-204

Sanders GE, Batts WN, Winton JR (2003) Susceptibility of zebrafish (Danio rerio) to a model pathogen, spring viremia of carp virus. Comp Med 53:514-521

Sheppard AM, Le Deuff RM, Martin PD, Woolford G, Way K, Stone DM (2007) Genotyping spring viraemia of carp virus and other piscine vesiculo-like viruses using reverse hybridisation. Dis Aquat Org 76:163-168

Stone DM, Ahne W, Denham KL, Dixon PF and others (2003) Nucleotide sequence analysis of the glycoprotein gene of putative spring viraemia of carp virus and pike fry rhabdovirus isolates reveals four genogroups. Dis Aquat Org 53:203-210

> Warg JV, Dikkeboom AL, Goodwin AE, Snekvik K, Whitney J (2007) Comparison of multiple genes of spring viremia of carp viruses isolated in the United States. Virus Genes 35: $87-95$

Submitted: July 18, 2008; Accepted: April 6, 2009 Proofs received from author(s): May 25, 2009 